\title{
Designing for Collective Intelligence and Community Resilience on Social Networks
}

\author{
JON CHAMBERLAIN, UNIVERSITY OF ESSEX \\ BENJAMIN TURPIN, UNIVERSITY OF ESSEX \\ MAGED ALI, UNIVERSITY OF ESSEX
}

KAKIA CHATSIOU, UNIVERSITY OF ESSEX

KIRSTY O’CALLAGHAN, ESSEX COUNTY COUNCIL

\begin{abstract}
The popularity and ubiquity of social networks has enabled a new form of decentralised online collaboration: groups of users gathering around a central theme and working together to solve problems, complete tasks and develop social connections. Groups that display such 'organic collaboration' have been shown to solve tasks quicker and more accurately than other methods of crowdsourcing. They can also enable community action and resilience in response to different events, from casual requests to emergency response and crisis management. However, engaging such groups through formal agencies risks disconnect and disengagement by destabilising motivational structures. This paper explores case studies of this phenomenon, reviews models of motivation that can help design systems to harness these groups and proposes a framework for lightweight engagement using existing platforms and social networks.
\end{abstract}

\section{INTRODUCTION}

The recent tragedies of the Grenfell tower block fire in London ${ }^{1}$ and Las Vegas Mandalay Bay shootings ${ }^{2}$ have something in common: the rapid and generous response of the community to help those affected by the events. In the former, displaced residents were welcomed into local residents' houses, local hotels offered free rooms and churches were turned into treatment centres (Sawer, 2017). In the latter, residents queued up through the night to give blood to those injured (Stump,

\footnotetext{
${ }^{1}$ https://en.wikipedia.org/wiki/Grenfell_Tower_fire, accessed 14/11/2018

${ }^{2}$ https://en.wikipedia.org/wiki/2017_Las_Vegas_shooting, accessed 14/11/2018
} 
2017). In both cases community action was mobilised by online communication through social networks.

Well-developed communities are capable of organising and solving their own needs; however, such activities are often undirected and lack resources. On a day-to-day basis individuals connect with each other in the community and gain personal satisfaction from involvement. It is in response to critical events such as flooding, fire, crime etc. that we can see resilient communities reacting and supporting each other quickly and effectively without coordination by a centralised government agent.

Crowdsourcing and citizen science projects have shown the willingness of the public to participate in projects they feel are worthwhile; however, interfacing digital communities with physical communities invokes a complex array of motivations, not only why people do things, but why they do not. Engaging such groups through formal agencies may risk destabilising motivational structures so careful consideration of the design of systems should be made.

We first review related work on volunteering approaches for community resilience and how social networks are playing an increasing role in the engagement and facilitation of online and real-world activity (Section 2). In Section 3, we discuss factors that can motivate user participation and engagement, as well as issues that may dissuade users. Finally, in Section 4 we discuss design considerations of systems of community coordination and propose a lightweight framework for collective intelligence and community resilience that addresses the socio-technical needs of online community groups and minimises the risk of disconnect and disengagement.

\section{RELATED WORK}

\subsection{Community resilience}

Interest in resilience developed throughout the 1970s, but it wasn't until thirty years later that researchers in emergency and disaster management, together with policy makers and emergency managers, began to embrace resilience thinking (Demiroz and Haase, 2018). Building disaster resilience in crisis prevention programme design has been a priority over the last decade not only for national governments (US President, 2010; United States of America, 2011) and the international community (United Nations Office for Disaster Risk Reduction, 2015), but also for local authorities, businesses, and other community actors (Aitsi-Selmi et al., 2015; Kelman and Glantz, 2015).

The concept of resilience has been challenging to define, even when focusing solely on disaster management and emergency planning literature. While many researchers agree that resilience is an important aspect of disaster prevention and recovery and a de facto policy goal (De Bruijne et al., 2010; Manyena et al., 2011), its exact scope varies depending on the background and viewpoints of those trying to define it. Demiroz and Haase summarise these as follows (Demiroz and Haase, 2018):

- a system's capacity to resist a disturbance such as system redundancy (Bruneau et al., 2003) or, for example, the use of reinforced construction techniques.

- a system's capacity to absorb a disturbance, in other words, to 'bounce back' or 'return to' the status quo such as how social capital (Aldrich, 2012) and government institutions (Davis and 
Robbin, 2015) can facilitate rapid restoration of social and lifeline services in the days and weeks after a disaster event.

- a system's capacity to adapt, or bounce forward, in response to a disturbance (Manyena et al., 2011) such as how disasters can serve as a 'catalyst for change' (Paton and Johnston, 2006).

This three-fold definition aligns with the way resilience is conceptualised in recent models of crisis planning, as the capacity of the system not only to be prepared for an event, and thereby minimise the impact, but also the capacity of a system to adapt where all of its actors have a stake in ensuring the system succeeds.

Tierney suggests that resilience is critical throughout the 4-stage hazards cycle (prevention, preparation, response and recovery) (Tierney, 2012). She discusses three types of resilience planning:

i. Anticipatory resilience planning - activities that enable communities to assess risk, form communities of interest, exercise foresight and enact mitigation and preparedness measures to manage risks;

ii. Responsive resilience planning - activities that enable groups and organisations to mobilise resources through interpersonal and inter-organisational networks, to carry out plans, and to improvise and exercise creativity when plans fall short;

iii. Adaptive resilience planning - activities that enable groups to reassess their circumstances, learn from experiences, and adjust strategies in light of the âĂ $\ddot{Y}$ new normalâĂŹ ushered in by disaster (Drennan and Morrisey, 2018).

In the Adaptive Resilience Model (Kapucu et al., 2013), widespread community engagement is a tool for building resilience. All relevant stakeholders and community members should be engaged in the process of recovery. At that point, effective communication and engagement can create and reinforce community resilience. Resilience arises in part from activities that bring people together to plan for such a shock (Tierney, 2012), and is characterised by a community's ability to improvise and coordinate with respect to the shock, and enhanced by engaging relevant groups to endure any ensuing crisis (Ross, 2014). Enabling such collaboration and engagement requires large-scale communication networks, such as those afforded by social media platforms, to coordinate and organise people and tasks.

\subsection{Social networks building resilience}

With reference to online or web communities in particular, Gray et al. make a distinction between 'organic collaboration', in which users self-organise work, and 'engineered collaboration' where workflows are built by requesters (an organisation or entity that wants tasks to be responded to) (Gray et al., 2016). This is discussed in more detail in later sections but it is a useful distinction between the following two approaches to engaging online volunteer communities.

\subsubsection{Engineered collaboration through micro-volunteering}

'Micro-volunteering' is an engineered approach that has been gaining popularity online, in particular where the tasks can be completed using only a smart phone or device at the convenience of the volunteer (Jones, 2017). A number of tools and websites exist for the purposes of managing projects that require microvolunteers, for example: 
- Neighbourly. $\mathrm{com}^{3}$ - allows organisations to connect to businesses and volunteers for donations of time, money and food;

- Nextdoor.com ${ }^{4}$ - real names and addresses entered by users to connect to people in localised areas. Task requests include borrowing items, social company, etc;

- Taskrabbit.co.uk ${ }^{5}$ - users can post tasks (including times to show up, qualifications required etc), then they select a responder who is paid on completion of the job;

- Rallyroundme. com $^{6}$ - connect with family members, friends and carers to organise support for an individual. Good for management of daily tasks for people with high needs;

- Sparked.com ${ }^{7}$ (skills for change) - microvolunteer online time to address challenges with different skill requirements;

- Helpfulpeeps.com ${ }^{8}$ - free to post tasks and offer time to help with users earning âĂIJkarma pointsâĂİ for helping out.

Micro-managed volunteering solutions (where the system only has one type of task) have achieved near-real time responses using workers maintained on a retainer to complete tasks when volunteers are not available (Bigham et al., 2010). Additionally, open source platforms such as Ushahidi ${ }^{9}$ allow for the development of customised projects for citizen-led engagement in civic activities (notably monitoring through mobile phone reporting).

Micro-volunteering projects have achieved varying degrees of success in terms of user engagement and tasks completed; the most significant hurdle to recruitment is getting users to sign up to the portal, register their information, and learn how the system works.

Conversely, we know that people are self-organising similar tasks using social media platforms with great success and high engagement. This is driven by the familiarity and reach of the systems used, as well as the ability of each user to manage their subscriptions, news feed and privacy, and provides them with fine-grained control over what they present of themselves and what information they receive. It has also been observed that users on microtask systems such as Mechanical Turk use social network groups to communicate task information and help complete tasks (Gray et al., 2016).

\subsubsection{Organic collaboration through social network groups}

Another way communities might choose to collaborate is via existing social network groups to distribute tasks to members with the relevant expertise or experience. Similar to the concept of crowdsourcing (where the work traditionally done by a single person is replaced by the collective action of a group of people via the Internet) (Howe, 2008), groupsourcing is defined as completing a task using a group of intrinsically-motivated people of varying expertise connected through a social network (Chamberlain, 2014). A group in this context is a feature of a social network platform

\footnotetext{
${ }^{3}$ https://www.neighbourly.com, accessed 11/11/2018.

${ }^{4}$ https://nextdoor.co.uk, accessed 11/11/2018.

${ }^{5} \mathrm{https}: / /$ www.taskrabbit.co.uk, accessed 11/11/2018.

${ }^{6} \mathrm{https}: / /$ rallyroundme.com, accessed 11/11/2018.

${ }^{7}$ http://skillsforchange.com, accessed 11/11/2018.

${ }^{8} \mathrm{https} / / /$ helpfulpeeps.com, accessed 11/11/2018.

${ }^{9}$ https://www.ushahidi.com, accessed 12/11/2020.
} 
that allows a small subset of users to communicate through a shared message system. Groups (for example, on Facebook) are initially set up in response to the needs of a few people and the community evolves as news from the group is proliferated around the network in feeds and user activity.

Social network groupsourcing is distinguished by several features:

- tasks are created by the users;

- communication is unconstrained and multi-threaded;

- users are inherently motivated, socially trained and work collaboratively;

- the output is immediately accessible and (potentially) beneficial to all, with users receiving recognition for their efforts.

One of the advantages of this approach is that the participants learn from each other, not only how to contribute to the system, but also the knowledge to participate. This interaction is led by more experienced and knowledgeable members of the community in an open and transparent way, meaning that when a user receives an answer from an expert, many more may be passively learning from it.

Social learning (Bandura and Walters, 1963), in which users on a platform teach and support each other in an ad-hoc manner, encourages users to engage in the learning process to an extent that suits their interests and time constraints.

Task-focused Facebook groups have been used to connect marine scientists and amateur enthusiasts to give insights into wildlife behaviour, distribution and morphology through dialogue centred around a task (see Figure 1) including:

- making observations of species;

- identifying new species;

- coordinating citizen science activities;

- managing the distribution of taxonomic knowledge (Chamberlain, 2018).

The community of users in these groups perform image classification tasks at near-expert levels on difficult tasks (0.93), considerably outperforming the same set of tasks on the Crowdflower microworking platform ${ }^{10}(0.49)$ (Chamberlain, 2014). These groups are self-organising in response to community needs and enable interactions that have an impact on community engagement.

Task-based social network groups demonstrate how these communities could be used for disaster response, with groups being setup where users are expecting tasks to be posted and responded to (for example, a group for crisis response) and others groups setup for sharing information and coordinating daily activities.

The organic collaboration within the online community already exists and manifests in numerous forms, from coordinating hyper-local action such as searching for a missing dog, through to wider responses to take action on local issues. Unlike other methods of crowdsourcing and citizen science, the people volunteering their time are doing so in undirected, but inherently motivated way.

\footnotetext{
${ }^{10}$ https://www.figure-eight.com, Crowdflower is now called Figure Eight.
} 


\section{Jon Chamberlain}

I was thinking this was Coryphella browni, but someone suggested it might be Facellina bostoniensis due to the long tentacles and more upright rhinophores. Any thoughts?
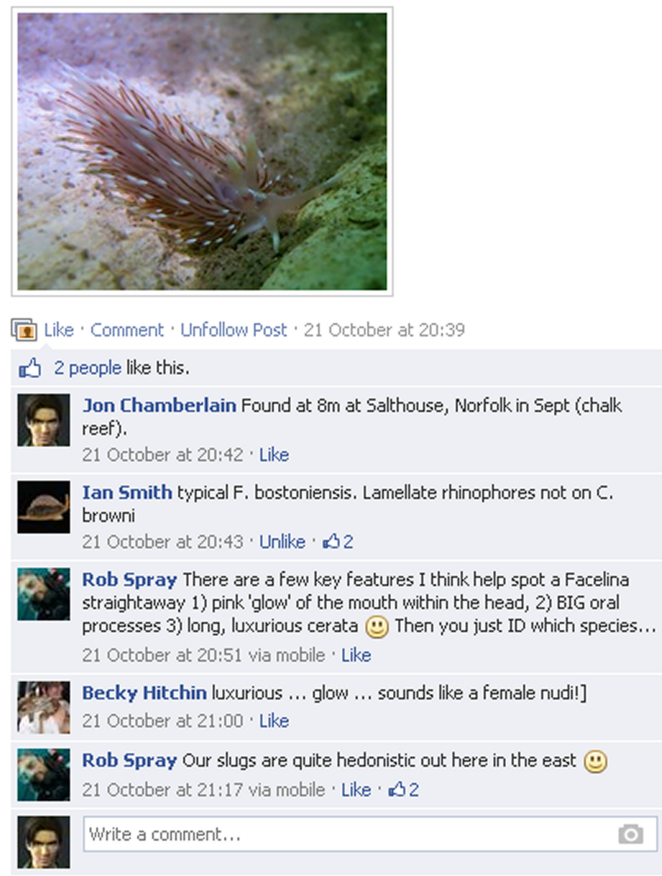

Figure 1. Example of how an image classification task is solved through discussion on Facebook groups.

\subsection{Summary}

The scope of community resilience can be defined as the capacity to resist, absorb and adapt to disturbances. Social networks can be used to support community resilience either through engineered collaboration, where a dedicated platform is setup to coordinate micro-volunteering, or through organic collaboration in social network groups. Both approaches play an increasing role in the engagement and facilitation of online and real-world community activity.

\section{ONLINE COMMUNITY PARTICIPATION}

As seen in case studies of collective action on social network groups, users are motivated and selforganised. However, in order to engage these groups, we must understand why they might participate and contribute to a collective effort and, perhaps more importantly, why they might not.

Users can be motivated in different ways, dependent on the system, task and goals, and the effectiveness can be measured by how much people participate and how much they contribute. Noncontributing members of a collective effort are common-place on social networking platforms, with 
most users simply viewing the content rather than contributing new content or commenting on existing information; however, there is a very low barrier for participation, in that a user can simply 'like' existing content rather than contributing new content.

It s well reported that the distribution of effort is never equal, commonly following a Zipf power law distribution (Zipf, 1949), in which only a few users make the majority of the contributions and this has been shown to hold across a number of other domains including social networking platforms (van Mierlo, 2014).

Crowston and Fagnot describe motivation arcs, which account for changes in motivation (and hence participation) over time, and investigate the prevalence of specific factors at different stages of participation (Crowston and Fagnot, 2008). Frameworks such as these aim to understand and model why people decide to get involved in an activity, and how their engagement continues beyond the initial contact.

From a broader perspective we must understand how participation is situated in the human experience, with a users' personal situation and interests changing over time, as well as their skills and experience. The personal circumstances of participants are highlighted as a major factor affecting involvement. For many participants of crowdsourcing, their involvement is strongly linked to the level of contact they have with coordinators, both in the design of the platform and in providing feedback on the impact of their contributions (Baruch et al., 2016).

This is reflected in the reported reasons of users contributing to citizen science portals, in which contributions tend to be largely driven by intrinsic reasons, including (i) the desire to help a worthy scientific cause, (ii) a personal interest in science, or (iii) the sense of belonging to a group of like-minded people (Raddick et al., 2010). This sense of working with task requesters, rather than for them, seems key to the "mentoring, skill-building and a sense of shared identity" observed on successful platforms (Gray et al., 2016).

\subsection{Motivation to Contribute}

There is a long history of using motivational theories to study the behaviour and participation of individuals in online communities (Maslow, 1943; Madsen, 1964). In many studies, Self-Determination Theory (SDT) has been used as a theoretical framework to help understand why people take part and contribute to online communities (Nov et al., 2010; Zhao and Zhu, 2012; Mekler et al., 2013, 2017). This is a macro theory of human motivation concerning people's inherent growth tendencies and their innate psychological needs based on two types of motivations: intrinsic and extrinsic (Brabham, 2013; Organisciak, 2008; Ryan and Deci, 2000b).

Intrinsic motivations are those which apply when the individual finds fulfilment in performing the activity and is core to participation online. Intrinsically motivated activities are those that the individual finds interesting and performs without any kind of conditioning, just by the mere pleasure of carrying them out. To maintain the intrinsic motivation in individuals, it is necessary to satisfy the following psychological and social needs:

- Autonomy, or the sense of will, when performing a task;

- Competence, the need of people when participating in challenges to feel competent and efficient;

- Relatedness, experienced when a person feels connected to others. 
Intrinsic motivation will be strengthened in relations that convey security, and by extension trust, and have been found to have a positive psychological effect, improving well-being, and thus increasing creativity, learning outcomes and quality of life (Hamari et al., 2014). Furthermore, the openness of the data resource being created and the transparency of the community that is creating it are crucial to user engagement (Lakhani et al., 2007; Dabbish et al., 2014).

Extrinsic motivations are related to the attainment of a goal (i.e., to gain a promotion), or some external outcome (e.g., a reward such as a financial gain). Intrinsic and extrinsic motivations are closely linked (Deci et al., 1999); however, the relationship between the two are often antagonistic (Ryan and Deci, 2000a; Cerasoli et al., 2014).

Other models of motivation describe a more complex motivational feature set. Moore and Serva articulate motivation factors based on correlating expressions, identifying 14 different categories of motivations, which cover intrinsic and extrinsic aspects (Altruism, Belonging, Collaboration, Egoism, Egotism attention-getting, Emotional Support, Empathy, Power, Reciprocity, Reputation, Self-Esteem, Self-Expression, Wisdom) (Moore and Serva, 2007) . Another example is the Reiss profile, a personality-based approach to assessing motivation; their approach identifies themes such as power, curiosity, social contact, status, and tranquillity (Reiss, 2004). Kraut et al. also name 16 basic desires related to personal motivations in their work on building successful online communities (Kraut et al., 2011).

\subsection{Disconnect and Disengagement}

Although it is important to understand ways in which community engagement can be fostered, it is also productive to consider the obstacles and deterrents that exist to prevent individuals from engaging in online communities. While less academic work has been conducted with this focus, it remains important to understand why individuals are reluctant, or unable, to engage in community activities in physical and digital spaces.

The most significant factor is likely to be a lack of motivation, as detailed in the previous section. However, even if an individual has the sufficient motivation to take part in a community project, there may be additional factors that prevent, or dissuade, them from doing so. For example, a study conducted by Kenis and Mathijs on individuals' motivations for engaging in collective action in relation to climate change indicated that a sense of powerlessness could be a significant deterrent (Kenis and Mathijs, 2012).

Digital communications and social media have been heralded as a ground-breaking means of encouraging communities to mobilise and perform collective action. However, a dependence on these spaces can result in the exclusion of those without the means, or motivation, to engage in online communications. Despite the fact that internet technology is now ubiquitous in many people's daily lives, it is false to presume that all have equal access to digital technology. There is a rich body of literature on the so-called 'digital divide', which indicates several demographic factors that influence access to digital technology. For example, the divisions of wealth, gender and ethnicity have an impact on individuals' access to online communities (Compaine, 2001; Norris, 2001) and there is still a digital divide between rural and urban communities (Philip et al., 2017). Rural, isolated communities in the UK still lack the degree of internet connectivity within cities, which can have a 
negative impact on rural community members' access to online government services (Choudrie and Weerakkody, 2005).

Internet access is not the only factor to consider when identifying obstacles that prevent individuals from engaging with internet-coordinated community projects. For example, differences between a user's online skill can have a strong influence on their ability to obtain information online (Hargittai, 2002) and a users' ability to efficiently access online information is often determined by age, with older users being less effective in obtaining information from online sources (Morris et al., 2007; Brandtzæg et al., 2011). Other factors that may prevent individuals from using digital technology as a means of communication include technophobia and ideological resistance to new technologies (Selwyn, 2003).

Even for those with access to social media networks, there remain a number of factors that can prevent users from utilising this technology to engage with community projects. Some of these deterrents stem from the very participatory nature of social media that makes it an attractive means of encouraging community engagement. A recent study indicated that social media users can be deterred from engaging in public communities due to anxieties surrounding 'trolling', or other forms of online harassment (Lutz and Hoffmann, 2017). An additional deterrent is the widespread public concern regarding the proliferation of 'fake news' over social media networks (Allcott and Gentzkow, 2017). There is urgent active research on this area, especially in relation to social media-led responses to crisis events, such the Manchester bombing in the UK, where false images of missing people were distributed over social media (Cresci, 2017). In cases such as these, trust can be a significant determining factor for whether a user engages with an online community (Abdul-Rahman and Hailes, 2000) and responds to a request.

An additional factor that can deter social media users from engaging with online communities stems from the volume of information that is disseminated on social media networks. Gomez-Rodriguez et al. use the term 'information overload' to describe situations where social media users receive information at a faster rate than they are able to process (Gomez-Rodriguez et al., 2014). As a user's online social network develops, individuals must develop skills in filtering relevant information from social media platforms. In these cases, users filter information based on idiosyncratic policies which ultimately determine what information is assimilated. The detrimental impact of information overload in social media use in relation to community action has been discussed in relation to emergency situations, where it is vital that accurate information is promptly disseminated via all available platforms (Hiltz and Plotnick, 2013). Information overload can also impair an individual's ability to take action, even if they identify the cause as worthy of involvement (Aldoory and Dyke, 2006).

There are significant factors that prevent potential users joining online communities (access to systems, user demographics and skills) or causing existing users to leave (sense of powerlessness, online harassment, fake news, breaches of trust and information overload). However, the reach of social network platforms is significantly greater than individual tasking platforms and online community groups forming on a large-scale with users intrinsically motivated to participate and contribute. 


\subsection{Summary}

Online systems that aim to coordinate community action must consider why users would participate and engage with tasks, and conversely why they would not. Addressing the psychosocial needs of users (autonomy, competence and connection) and how intrinsic and extrinsic factors influence these needs is essential to developing and sustaining a community of online users that can translate into real-word action. However, not all members of a community will be willing or able to participate and consideration for more inclusive modes of engagement should be made.

\section{A FRAMEWORK FOR COLLECTIVE INTELLIGENCE AND COMMUNITY RESILIENCE}

The aim of the framework is to facilitate the engagement of volunteers within online communities, requiring minimal oversight from administrators, and to keep as much functionality on the preferred system of the volunteer without replicating it in another place. This is in the spirit of platforms that offer access to their systems via an API. A light touch is required to ensure existing activity continues and what is offered augments the engagement online.

By developing additional functionality to work alongside existing social networks such as Facebook, challenges of mobilising a physical volunteer force can be addressed, such as trust, reputation, protection for vulnerable community members, etc. Some tasks will not require detailed information about the volunteer (e.g. a community litter pick); however, other tasks will require some knowledge of the volunteer (e.g., accessing an elderly person's home to do a task). Pre-checks and task feedback will allow requesters to select the most appropriate volunteer(s) for the task.

Design and implementation of the framework would usefully follow guidelines suggested for using Facebook groups in healthcare management (Partridge et al., 2018):

i. Iterative development with input from the target users;

ii. Understanding the potential role of group 'champions';

iii. Ensuring the social media policies of organisations allow for real time online communication;

iv. Utilising comprehensive evaluation strategies, including the use of process evaluations.

In what follows, we elaborate on the design considerations, explain the framework information flow and discuss its benefits and limitations. We also provide an example of how this framework is being applied to build social capital in the county of Essex, UK.

\subsection{Design considerations}

\subsubsection{Emergency response vs community coordination}

The first consideration is what type of interaction and response is required from the online community. Is the goal for rapid action in the event of rare but serious crisis events (such as an earthquake) or for community resilience to regular, less-critical events and tasks (such as supporting local services for social care)? In the former case the system would be required to inform users of activity, to coordinate response and for the users to know where to go for the information. However, whilst users may frequent a social network platform, a group that rarely posts requests will be not keep 


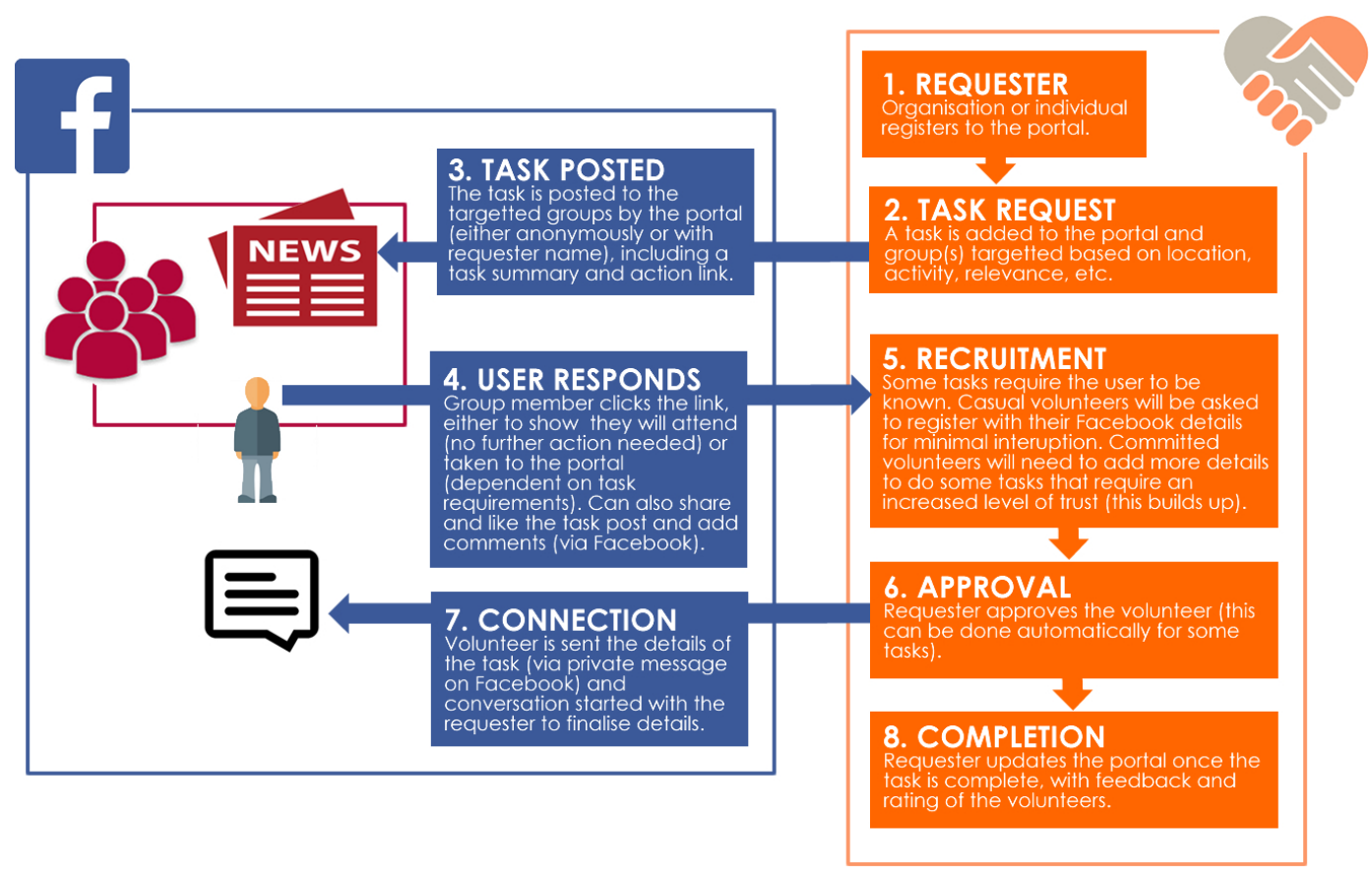

Figure 2. Proposed lightweight framework (right) for augmenting existing social network group workflows (left).

users engaged. By building on groups that are active daily and the workflow more embedded in their online and real-world lives, community resilience to disturbance events can be facilitated quicker with greater reach.

Response time and lifespan of messages are influenced by the interface design of each social networking platform (Chamberlain, 2014). In Facebook, for example, when messages are first posted they appear on a user's news feed and/or notifications and the group wall. Over time they are replaced with other messages, move down the page until no longer visible and can only be accessed by clicking for older pages. If a message receives a reply it is moved back to the top of the page (termed 'bumping'). Whilst it is possible to use a framework to manage the distribution of messages to the group, it is the platform that controls how they are displayed to the end user based on their individual settings and preferences.

\subsubsection{Skill requirements}

Tasks require different levels of skill, experience and knowledge (as well as qualifications and accreditation) so it is important to consider how responding users can be judged for their ability to successfully complete the task; however, the distinction between users of different abilities is not straightforward (Brabham, 2012). Tasks that require group effort or collective intelligence may be at risk of expert bias, in which systems can be manipulated (intentionally or otherwise) by the perceived ability of an expert user (Alon et al., 2015). This is a long-standing issue in research areas of 
reputation management, expert finding and recommender systems; however, it is intuitive to believe that knowledgeable users in social networks groups are beneficial to the community. There is also a danger of convergence towards the opinions of charismatic members or the majority, with minority valid opinions being ignored. The unconstrained input of social networks allows users to address this by forming divergent discussion and action points.

\subsubsection{Automatic processing of message threads}

Volunteer responses on social network platforms occur through the natural language of the message thread and a significant challenge is the automatic processing of these threads. Messages and replies can be simply categorised by inquisition (question or task request) and data load (solution to the task) (Chamberlain, 2014), although more detailed schemas (Bunt et al., 2012) and richer feature sets (Agichtein et al., 2008) have been used to describe dialogue.

There are a large quantity of data associated with threads and removing this overhead is essential when processing on a large scale (Maynard et al., 2012). The natural language processing also needs to cope with ill-formed grammar and spelling, and sentences for which only context could make sense of the meaning.

Aggregating the social network data in a similar way to crowdsourcing will allow for the automatic extraction of knowledge and sophisticated crowd aggregation techniques (Raykar et al., 2010) can be used to gauge the confidence of data extracted from threads. However, a simple validation model features in some form on most social network platforms: a 'like' or 'upvote' button can be found on messages and replies, allowing the community to show favour for particular solutions. Other forms of voting exist, such graded voting (using a five star vote system) allowing for more finegrained analysis of the community's preference and further research is needed to assess whether this is an efficient way of using human effort when a simple 'like' button may be just as effective (Chamberlain et al., 2018).

\subsection{Framework information flow}

The process diagram (see Figure 2) shows how tasks can be created, shared and responded to by administrators on a portal, whilst the users' interaction remains on their preferred social networking platform.

i. The first step is for a requester (an organisation or an individual that requires a task to be completed) to register to the portal.

ii. The task is added to the portal and different groups are targeted based on location, activity, relevance, etc.

iii. The task is then posted to targeted groups by the portal (either anonymously or with a requester's name attached). The post includes a task summary and an action link.

iv. Within their preferred social networking platform interface, a group member interested in the task can click on the link. They go on to confirm they will attend or take ownership of the task (in which case the task is marked as done or requiring no further action). Depending on the task, they can also be redirected to the portal, share/like the task post and add comments (such as, for example, via Facebook comments). 
v. Where tasks require users (either previously known to the requesters or having specific characteristics or expertise), these users will need to be already registered to the portal before they can be assigned to a task, to ensure minimal interruption. Committed volunteers will need to add more details to do some tasks that require an increased level of trust (which could be dependent on experience or expertise).

vi. The requester will approve the volunteer (this can be done automatically for some tasks).

vii. The volunteer will then be sent the details of the task (via private message) and a conversation may begin with the requester to finalise the details of the task.

viii. Once the task is complete, the requester can update the portal with feedback and rating of the volunteers.

The framework we propose has the benefit of reinforcing existing networks and tapping into them, with minimal disruption and a quick learning curve. The framework complements and reinforces existing organic collaboration and does not try to replicate it with an engineered approach (such as platforms mentioned in Section 2.2.1). The framework makes it possible for administrators in crisis management (both voluntary and government led) to use it as a tool to build resilience in the communities they serve before and after a crisis event.

\subsection{Limitations}

The benefits of online social networks have been studied extensively both in users' day-to-day interactions (Ellison et al., 2007) as well as in crisis contexts (White, 2016). Communities are using social networks to forge connections, reduce social isolation, help each other in times of trouble or simply let their loved ones know that they are ok in times of crisis or where other means of communication are not possible.

Despite the many benefits of social networking platforms, there are also some significant limitations. The constantly changing underlying technology, as well as the popularity with users, means that long-term projects need to spend more time adjusting their software to maintain compliance. Although fairly mature with a high take-up rate, social networking platforms are still an emerging technology, and changes are often made to the terms of service, access and software language that could swiftly render a dependent platform redundant.

Another drawback to using social networking platforms is that people use them in different ways and there is no formally correct way. Additionally, our understanding of such systems is only through observation as the algorithms for presenting information are never published and are constantly changing. There are also a proportion of user accounts used for spreading advertising, misinformation and spam. Users have different cultural expectations that may lead to segregation and discrimination in groups.

It is unclear in the long term how social networking will continue as a popular pastime, and maintaining a community's interest in a project over time will need to be carefully managed. There may also be a saturation point of how many projects can be implemented to existing communities and this is also a problem for other crowdsourcing approaches. 


\subsection{An example: Location-based social network groups building social cap- ital in Essex, UK}

In 2015/16 Essex County Council (ECC) spent approx. $£ 180$ million on meeting the social care needs for adults with learning disabilities (approx. 20\% of the total council budget). Additionally, across the county of Essex (UK) $31 \%$ of older people aged 65+ are estimated to have some form of social care need and this is projected to increase by $63 \%$ over the next 20 years (Dean, 2012). Surveys of ECC volunteer centres indicated they could not meet this increasing service demand and that potential community volunteers do not participate (or continue to participate) due to limitations caused by formal volunteering, in particular, regularity of time and the bureaucracy involved. Therefore ECC investigated social network groups to strengthen social capital (both digital and physical) within Essex communities and to increase resilience to adverse events, reduce social isolation and encourage citizens to help themselves and others.

ECC commissioned a survey in 2017 that showed there were over 150 Facebook groups that incorporate some degree of local volunteering in Essex, with a total of 946k users (although this is likely to be an over-estimation as some users will be registered to multiple groups). These groups were self-organising and not created nor managed by ECC themselves. Users post tasks or offers for help, with group dynamics shifting in response to community needs.

An example of how ECC successfully used Facebook groups to facilitate community resilience was to offer mental health training (supporting a need identified by the community) via a local Facebook group. Within a month 80 volunteers had received Mental Health accredited first aid training and committed to supporting people within their community with a mental health issue.

Engagement with the community through social network groups presents a significant challenge for ECC, with policies covering duty of care, data protection and reporting/oversight all affected; however, their successful outreach has encouraged investment in using this approach in the future through the framework proposed here. The effectiveness of such a framework, in comparison to either an engineered solution, microvolunteering or organic collaboration, must consider a number of factors: value for money (development and ongoing costs); time to implement; user take up; data protection; user protection; load balancing; coverage; sustainability; etc. It would be difficult to make a direct assessment of task performance for the kind of tasks that support community resilience e.g., in the way outlined in (Chamberlain, 2014); however, proxy measures of user engagement and satisfaction could also be used to evaluate the impact of the framework.

\section{CONCLUSION}

The development of user groups on social networks increases community resilience by enabling connectivity between individuals, reduces social isolation by facilitating communication and encourages citizens to help each other by mobilising activities that require participation.

These groups form organically and are self-organising with users intrinsically motivated to participate and contribute. However, there are significant factors that prevent potential users joining (access to systems, user demographics and skills) or causing existing users to leave (sense of powerlessness, online harassment, fake news, breaches of trust and information overload).

If lightweight frameworks can be built to address such considerations, whilst fostering the organic 
collaboration that is inherent on social networks, it is possible to tap into a huge resource of collective intelligence and community activism.

\section{ACKNOWLEDGEMENTS}

The authors would like to acknowledge the valuable assistance of Asa Aldis and Jon Morter in preparing the data for this research.

\section{DISCLOSURE STATEMENT}

The authors are not aware of any potential conflicts of interests.

\section{FUNDING}

This research was partially funded from the ESRC Impact Acceleration Account ES/M500537/1.

\section{REFERENCES}

Abdul-Rahman, A and Hailes, S. (2000). Supporting Trust in Virtual Communities. In Proceedings of the 33rd Hawaii International Conference on System Sciences (HICSS '00), Vol. 6. IEEE Computer Society, Washington, DC, USA.

Agichtein, E, Castillo, C, Donato, D, Gionis, A, and Mishne, G. (2008). Finding High-quality Content in Social Media. In Proceedings of the 1st ACM International Conference on Web Search and Data Mining (WSDM'08). 183-194.

Aitsi-Selmi, A, Egawa, S, Sasaki, H, Wannous, C, and Murray, V. (2015). The Sendai Framework for Disaster Risk Reduction: Renewing the Global Commitment to PeopleâĂŹs Resilience, Health, and Well-being. International Journal of Disaster Risk Science 6, 2 (2015), 164-176. DOI : http://dx.doi.org/10.1007/s13753-015-0050-9

Aldoory, L and Dyke, M. A. V. (2006). The Roles of Perceived âĂIJSharedâĂİ Involvement and Information Overload in Understanding How Audiences make Meaning of News about Bioterrorism. Journalism \& Mass Communication Quarterly 83, 2 (2006), 346-361. DOI : http://dx.doi.org/10.1177/107769900608300208

Aldrich, D. P. (2012). Building Resilience: Social Capital in Post-Disaster Recovery. University of Chicago Press.

Allcott, H and Gentzkow, M. (2017). Social Media and Fake News in the 2016 Election. Working Paper 23089. National Bureau of Economic Research. DOI : http://dx.doi.org/10.3386/w23089

Alon, N, Feldman, M, Lev, O, and Tennenholtz, M. (2015). How Robust Is the Wisdom of the Crowds?. In Proceedings of the 24th International Joint Conference on Artificial Intelligence, IJCAI'15. 2055-2061.

Bandura, A and Walters, R. H. (1963). Social learning and personality development. Holt Rinehart and Winston, New York.

Baruch, A, May, A, and Yu, D. (2016). The motivations, enablers and barriers for voluntary participation in an online crowdsourcing platform. Computers in Human Behavior 64 (2016), 923 - 931. DOI : http://dx.doi.org/10.1016/j.chb.2016.07.039

Bigham, J. P, Jayant, C, Ji, H, Little, G, Miller, A, Miller, R. C, Miller, R, Tatarowicz, A, White, B, White, S, and Yeh, T. (2010). VizWiz: Nearly Real-time Answers to Visual Questions. In Proceedings of the 23Nd Annual ACM Symposium on User Interface Software and Technology (UIST '10). ACM, New York, NY, USA, 333-342. DOI : http://dx.doi.org/10.1145/1866029.1866080

Brabham, D. C. (2012). The Myth of Amateur Crowds. Information, Communication and Society 15, 3 (2012), $394-410$.

Brabham, D. C. (2013). Crowdsourcing. The MIT Press.

Brandtzæg, P. B, Heim, J, and Karahasanović, A. (2011). Understanding the New Digital divide - A Typology of Internet Users in Europe. Int. J. Hum.-Comput. Stud. 69, 3 (2011), 123-138. DOI : http://dx.doi.org/10.1016/j.ijhcs.2010.11.004

Bruneau, M, Chang, S. E, Eguchi, R. T, Lee, G. C, OâÁŹRourke, T. D, Reinhorn, A. M, Shinozuka, M, Tierney, K, Wallace, W. A, and von Winterfeldt, D. (2003). A Framework to Quantitatively Assess and Enhance the Seismic Resilience of Communities. Earthquake Spectra 19, 4 (2003), 733-752. DOI : http://dx.doi.org/10.1193/1.1623497

Bunt, H, Alexandersson, J, Choe, J.-W, Fang, A. C, Hasida, K, Petukhova, V, Popescu-Belis, A, and Traum, D. (2012). ISO 24617-2: A semantically-based standard for dialogue annotation. In Proceedings of the 8th International Conference on Language Resources and Evaluation (LREC'12) (23-25). 
Cerasoli, C. P, Nicklin, J. M, and Ford, M. T. (2014). Intrinsic motivation and extrinsic incentives jointly predict performance: A 40-year meta-analysis. Psychological Bulletin 140 (2014), 980-1008. Issue 4. DOI : http://dx.doi.org/10.1037/a0035661

Chamberlain, J. (2014). Groupsourcing: Distributed Problem Solving Using Social Networks. In Proceedings of 2nd AAAI Conference on Human Computation and Crowdsourcing (HCOMP'14).

Chamberlain, J. (2018). Using Social Media for Biomonitoring: How Facebook, Twitter, Flickr and Other Social Networking Platforms Can Provide Large-Scale Biodiversity Data. In Next Generation Biomonitoring: Part 2, David A. Bohan, Alex J. Dumbrell, Guy Woodward, and Michelle Jackson (Eds.). Advances in Ecological Research, Vol. 59. Academic Press, 133 - 168. DOI : http://dx.doi. org/10.1016/bs.aecr.2018.06.001

Chamberlain, J, Kruschwitz, U, and Poesio, M. (2018). Optimising Crowdsourcing Efficiency: Amplifying Human Computation with Validation. it - Information Technology 60 (2018).

Choudrie, J and Weerakkody, V. (2005). Exploring E-Government in the UK: Challenges, Issues and Complexities. Journal of Information Science and Technology 2 (01 2005).

Compaine, B. M (Ed.). (2001). The Digital Divide: Facing a Crisis or Creating a Myth? MIT Press, Cambridge, MA, USA.

Cresci, E. (2017). The Story behind the Fake Manchester Attack Victims. (2017). http://www.theguardian.com/technology/2017/may/ 26/the-story-behind-the-fake-manchester-attack-victims Accessed 23/11/2017.

Crowston, K and Fagnot, I. (2008). The motivational arc of massive virtual collaboration. In Proceedings of the IFIP WG 9.5 Working Conference on Virtuality and Society: Massive Virtual Communities. Lüneberg, Germany.

Dabbish, L, Stuart, H. C, Tsay, J, and Herbsleb, J. D. (2014). Transparency and Coordination in Peer Production. Computing Research Repository (CoRR) abs/1407.0377 (2014).

Davis, G. L and Robbin, A. (2015). Network Disaster Response Effectiveness: The Case of ICTs and Hurricane Katrina. Journal of Homeland Security and Emergency Management 12, 3 (2015). DOI : http://dx.doi.org/10.1515/jhsem-2014-0087

De Bruijne, M, Boin, A, and Van Eeten, M. (2010). Resilience: Exploring the concept and its meanings. In Designing resilience: Preparing for extreme events, Louise K. Comfort, Arjen Boin, and Chris C. Demchak (Eds.). University of Pittsburgh Press, Pittsburgh, 13-32.

Dean, C. (2012). Joint Strategic Needs Assessment (JSNA). (2012). https://www.essexinsight.org.uk/Resource.aspx?GroupID=19\& ResourceID=301 Accessed 11/11/2018.

Deci, E. L, Koestner, R, and Ryan, R. M. (1999). A Meta-Analytic Review of Experiments Examining the Effects Of Extrinsic Rewards on Intrinsic Motivation. Psychological Bulletin 125 (1999), 627-668.

Demiroz, F and Haase, T. W. (2018). The concept of resilience: a bibliometric analysis of the emergency and disaster management literature. Local Government Studies (2018), 1-20. DOI : http://dx.doi.org/10.1080/03003930.2018.1541796

Drennan, L and Morrisey, L. (2018). Resilience Policy in Practice - Surveying the Role of Community Based Organisations in Local Disaster Managements. Local Government Studies (2018).

Ellison, N. B, Steinfield, C, and Lampe, C. (2007). The benefits of Facebook âĂIJfriends:âĂİ Social capital and college studentsâĂŹ use of online social network sites. Journal of computer-mediated communication 12, 4 (2007), 1143-1168.

Gomez-Rodriguez, M, Gummadi, K. P, and Schölkopf, B. (2014). Quantifying Information Overload in Social Media and its Impact on Social Contagions. CoRR abs/1403.6838 (2014).

Gray, M. L, Suri, S, Ali, S. S, and Kulkarni, D. (2016). The Crowd is a Collaborative Network. In Proceedings of the 19th ACM Conference on Computer-Supported Cooperative Work \& Social Computing (CSCW '16). ACM, New York, NY, USA, $134-147$. DOI : http://dx.doi.org/10.1145/2818048.2819942

Hamari, J, Koivisto, J, and Sarsa, H. (2014). Does Gamification Work? - A Literature Review of Empirical Studies on Gamification. In Proceedings of the 2014 47th Hawaii International Conference on System Sciences (HICSS '14). IEEE Computer Society, Washington, DC, USA, 3025-3034. DOI : http://dx.doi.org/10.1109/HICSS.2014.377

Hargittai, E. (2002). Second-Level Digital Divide: Differences in People's Online Skills. First Monday 7, 4 (2002).

Hiltz, S. R and Plotnick, L. (2013). Dealing with information overload when using social media for emergency management: Emerging solutions. In 10th Proceedings of the International Conference on Information Systems for Crisis Response and Management.

Howe, J. (2008). Crowdsourcing: Why the power of the crowd is driving the future of business. Crown Publishing Group.

Jones, C. (2017). Microvolunteering: what is it and why should you do it? (2017). https://www.theguardian.com/ voluntary-sector-network/2017/apr/13/microvolunteering-what-is-it-and-why-should-you-do-it Accessed 11/11/2018.

Kapucu, N, Hawkins, C. V, and Rivera, F. I. (2013). Disaster resiliency: interdisciplinary perspectives. Routledge, New York. OCLC: 
823388809.

Kelman, I and Glantz, M. H. (2015). Analyzing the Sendai Framework for Disaster Risk Reduction. International Journal of Disaster Risk Science 6, 2 (2015), 105-106. DOI : http://dx.doi.org/10.1007/s13753-015-0056-3

Kenis, A and Mathijs, E. (2012). Beyond individual behaviour change: the role of power, knowledge and strategy in tackling climate change. Environmental Education Research 18 (2012), 45 - 65.

Kraut, R. E, Resnick, P, Kiesler, S, Burke, M, Chen, Y, Kittur, N, Konstan, J, Ren, Y, and Riedl, J. (2011). Building Successful Online Communities: Evidence-Based Social Design. MIT Press.

Lakhani, K. R, Jeppesen, L. B, Lohse, P. A, and Panetta, J. A. (2007). The Value of Openness in Scientific Problem Solving. Working Paper 07-050. Harvard Business School.

Lutz, C and Hoffmann, C. P. (2017). The dark side of online participation: exploring non-, passive and negative participation. Information, Communication \& Society 20, 6 (2017), 876-897. DOI : http://dx.doi.org/10.1080/1369118X.2017.1293129

Madsen, K. (1964). Theories of motivation. Howard Allen.

Manyena, S. B, O'Brien, G, O'Keefe, P, and Rose, J. (2011). Disaster resilience: a bounce back or bounce forward ability? Local Environment 16, 5 (2011), 417-424. DOI : http://dx.doi.org/10.1080/13549839.2011.583049

Maslow, A. H. (1943). A Theory of Human Motivation. Psychological Review 50, 4 (1943), 430-437.

Maynard, D, Bontcheva, K, and Rout, D. (2012). Challenges in developing opinion mining tools for social media. Proceedings of the 8th International Conference on Language Resources and Evaluation (LREC'12)Workshop @NLP can u tag \#user_generated_content (2012).

Mekler, E. D, Brühlmann, F, Opwis, K, and Tuch, A. N. (2013). Disassembling Gamification: The Effects of Points and Meaning on User Motivation and Performance. In CHI'13 Extended Abstracts on Human Factors in Computing Systems (CHI EA '13). ACM, New York, NY, USA, 1137-1142. DOI : http://dx.doi.org/10.1145/2468356.2468559

Mekler, E. D, Brühlmann, F, Tuch, A. N, and Opwis, K. (2017). Towards Understanding the Effects of Individual Gamification Elements on Intrinsic Motivation and Performance. Comput. Hum. Behav. 71, C (2017), 525-534. DOI : http://dx.doi.org/10.1016/j.chb.2015. 08.048

Moore, T. D and Serva, M. A. (2007). Understanding Member Motivation for Contributing to Different Types of Virtual Communities: A Proposed Framework. In Proceedings of the 2007 ACM SIGMIS CPR Conference on Computer Personnel Research: The Global Information Technology Workforce (SIGMIS CPR '07). ACM, New York, NY, USA, 153-158. DOI: http://dx.doi.org/10.1145/1235000.1235035

Morris, A, Goodman, J, and Brading, H. (2007). Internet use and non-use: views of older users. Universal Access in the Information Society 6, 1 (2007), 43-57.

Norris, P. (2001). Digital divide: civic engagement, information poverty, and the Internet worldwide. Cambridge University Press Cambridge ; New York. xv, 303 p. : pages.

Nov, O, Anderson, D, and Arazy, O. (2010). Volunteer Computing: A Model of the Factors Determining Contribution to Communitybased Scientific Research. In Proceedings of the 19th International Conference on World Wide Web (WWW'10). ACM, New York, NY, USA, 741-750. DOI : http://dx.doi.org/10.1145/1772690.1772766

Organisciak, P. (2008). Motivation of Crowds: The Incentives That Make Crowdsourcing Work. (2008). http://crowdstorming. wordpress.com/2008/01/31 Accessed 13/11/2018.

Partridge, S. R, Gallagher, P, Freeman, B, and Gallagher, R. (2018). Facebook Groups for the Management of Chronic Diseases. J Med Internet Res 20, 1 (2018), e21. DOI : http://dx.doi.org/10.2196/jmir.7558

Paton, D and Johnston, D. M (Eds.). (2006). Disaster resilience: an integrated approach. Charles C Thomas, Springfield, Ill. OCLC: ocm65065531.

Philip, L, Cottrill, C, Farrington, J, Williams, F, and Ashmore, F. (2017). The digital divide: Patterns, policy and scenarios for connecting the âĂŸfinal fewâĂŹ in rural communities across Great Britain. (2017). DOI : http://dx.doi.org/10.1016/j.jrurstud.2016.12.002

Raddick, M. J, Bracey, G, Gay, P. L, Lintott, C. J, Murray, P, Schawinski, K, Szalay, A. S, and Vandenberg, J. (2010). Galaxy Zoo: Exploring the Motivations of Citizen Science Volunteers. Astronomy Education Review 9, 1 (2010).

Raykar, V. C, Yu, S, Zhao, L. H, Valadez, G. H, Florin, C, Bogoni, L, and Moy, L. (2010). Learning From Crowds. Journal of Machine Learning Research 11 (2010), 1297-1322.

Reiss, S. (2004). Multifaceted Nature of Intrinsic Motivation: The Theory of 16 Basic Desires. Review of General Psychology 8,3 (2004), 179-193. 
32 J. Chamberlain et al. / Human Computation (2021) 8:2

Ross, A. D. (2014). Local disaster resilience: Administrative and political perspectives. Vol. 9. Routledge, New York. DOI :http: //dx.doi.org/10.1111/1468-5973.12043

Ryan, R. M and Deci, E. L. (2000)a. Intrinsic and Extrinsic Motivations: Classic Definitions and New Directions. Contemporary Educational Psychology 25, 1 (2000), 54 - 67.

Ryan, R. M and Deci, E. L. (2000)b. Self-determination theory and the facilitation of intrinsic motivation, social development, and well-being. (2000). DOI : http://dx.doi.org/10.1037/0003-066X.55.1.68

Sawer, P. (2017). "It's Blitz spirit": Community centres and churches overwhelmed with donations for Grenfell Tower residents. (2017). https://www.telegraph.co.uk/news/2017/06/14/community-centres-churches-overwhelmed-donations-grenfell-tower Accessed 11/11/2018.

Selwyn, N. (2003). Apart from technology: understanding people's non-use of information and communication technologies in everyday life. Technology in Society 25, 1 (2003), 99-116.

Stump, S. (2017). Long lines to donate blood in Las Vegas, but more will be needed. (2017). https://www.today.com/health/ people-lining-give-blood-las-vegas-after-mass-shooting-t116958 Accessed 11/11/2018.

Tierney, K. (2012). Foreword. In Disaster resiliency: interdisciplinary perspectives., Naim Kapucu, Christopher V Hawkins, and Fernando I Rivera (Eds.). Routledge, New York, xiii-xvi. OCLC: 883648821.

United Nations Office for Disaster Risk Reduction, . (2015). Sendai Framework for Disaster Risk Reduction 2015-2030 - UNISDR. Technical Report. United Nations, Sendai, Japan. https://www.unisdr.org/we/inform/publications/43291

United States of America, . (2011). Presidential Policy Directive 8: National Preparedness. (2011). https://www.dhs.gov/ presidential-policy-directive-8-national-preparedness

US President, . (2010). The National Security Strategy of the United States of America. Technical Report. Executive Office of the President, Washington, D.C. 60 pages. http://nssarchive.us/national-security-strategy-2010/

van Mierlo, T. (2014). The 1\% Rule in Four Digital Health Social Networks: An Observational Study. Journal of Medical Internet Research 16, 2 (04 Feb 2014), 33.

White, C. M. (2016). Social media, crisis communication, and emergency management: Leveraging Web 2.0 technologies. CRC press.

Zhao, Y and Zhu, Q. (2012). Exploring the Motivation of Participants in Crowdsourcing Contest.. In ICIS. Association for Information Systems.

Zipf, G. K. (1949). Human Behavior and the Principle of Least Effort. Addison-Wesley. 